Article

\title{
Luminescent and Magnetic Tb-MOF Flakes Deposited on Silicon
}

\author{
Elena Bartolomé 1,*(D), Ana Arauzo ${ }^{2}$ (D), Sergio Herce ${ }^{3}$, Anna Palau ${ }^{3}{ }^{\mathbb{D}}$, Narcis Mestres ${ }^{3}$, Sara Fuertes ${ }^{4}$, \\ Pablo Sevilla ${ }^{1}$, Nicholas S. Settineri ${ }^{5,6}$, Laura Navarro-Spreafico ${ }^{7}$, Jonay González ${ }^{7}$ and E. Carolina Sañudo ${ }^{7,8, * \mathbb{D}}$
}

1 Department of Mechanical Engineering, Escola Universitària Salesiana de Sarrià (EUSS), Passeig de Sant Joan Bosco 74, 08017 Barcelona, Spain; psevilla@euss.es

2 Instituto de Nanociencia y Materiales de Aragón (INMA), CSIC-Universidad de Zaragoza, 50009 Zaragoza, Spain; aarauzo@unizar.es

3 Institut de Ciència de Materials de Barcelona (ICMAB-CSIC), 08017 Barcelona, Spain; sherce@icmab.es (S.H.); palau@icmab.es (A.P.); narciss@icmab.es (N.M.)

4 Departamento de Química Inorgánica, Facultad de Ciencias, Instituto de Síntesis Química y Catalisis, Homogénea (ISQCH), CSIC-Universidad de Zaragoza, 50009 Zaragoza, Spain; sfuertes@unizar.es

5 Advanced Light Source, Lawrence Berkeley National Laboratory, Berkeley, CA 94720, USA; nsettine@berkeley.edu

6 Department of Chemistry, University of California, Berkeley, Berkeley, CA 94720, USA

7 Secció de Química Inorgànica, Departament de Química Inorgànica i Orgànica Universitat de Barcelona, C/Martí i Franquès, 1-11, 08028 Barcelona, Spain; laura.spre@gmail.com (L.N.-S.); jgonzasa22@alumnes.ub.edu (J.G.)

8 Institut de Nanociència i Nanotecnologia, IN2UB, C/Martí i Franqués 1-11, Universitat de Barcelona, 08028 Barcelona, Spain

check for updates

Citation: Bartolomé, E.; Arauzo, A.; Herce, S.; Palau, A.; Mestres, N.; Fuertes, S.; Sevilla, P.; Settineri, N.S.; Navarro-Spreafico, L.; González, J.; et al. Luminescent and Magnetic Tb-MOF Flakes Deposited on Silicon. Molecules 2021, 26, 5503. https:// doi.org/10.3390/molecules26185503

Academic Editor: Dawid Pinkowicz

Received: 23 July 2021

Accepted: 4 September 2021

Published: 10 September 2021

Publisher's Note: MDPI stays neutral with regard to jurisdictional claims in published maps and institutional affiliations.

Copyright: (C) 2021 by the authors. Licensee MDPI, Basel, Switzerland. This article is an open access article distributed under the terms and conditions of the Creative Commons Attribution (CC BY) license (https:/ / creativecommons.org/licenses/by/ $4.0 /)$.
* Correspondence: ebartolome@euss.es (E.B.); esanudo@ub.edu (E.C.S.)

Abstract: The synthesis of a terbium-based 2D metal-organic framework (MOF), of formula $\left[\mathrm{Tb}(\mathrm{MeCOO})(\mathrm{PhCOO})_{2}\right](\mathbf{1})$, a crystalline material formed by neutral nanosheets held together by Van der Waals interactions, is presented. The material can be easily exfoliated by sonication and deposited onto different substrates. Uniform distributions of Tb-2D MOF flakes onto silicon were obtained by spin-coating. We report the luminescent and magnetic properties of the deposited flakes compared with those of the bulk. Complex $\mathbf{1}$ is luminescent in the visible and has a sizeable quantum yield of QY $=61 \%$ upon excitation at $280 \mathrm{~nm}$. Photoluminescence measurements performed using a micro-Raman set up allowed us to characterize the luminescent spectra of individual flakes on silicon. Magnetization measurements of flakes-on-silicon with the applied magnetic field in-plane and out-of-plane display anisotropy. Ac susceptibility measurements show that $\mathbf{1}$ in bulk exhibits field-induced slow relaxation of the magnetization through two relaxation paths and the slowest one, with a relaxation time of $\tau_{\text {lf }} \approx 0.5 \mathrm{~s}$, is assigned to a direct process mechanism. The reported exfoliation of lanthanide 2D-MOFs onto substrates is an attractive approach for the development of multifunctional materials and devices for different applications.

Keywords: 2D MOFs; lanthanides; luminescence; magnetic anisotropy; exfoliation; flakes

\section{Introduction}

Two-dimensional (2D) materials are receiving growing interest owing to their huge potential for application in electronics [1], energy storage [2-4], catalysis [5], sensing, biomedicine [6], etc., and the intriguing new physics appearing at the 2D limit $[7,8]$.

While most well-studied 2D materials are inorganic solids, such as the very wellknown graphene [9], recent advances in coordination chemistry have enabled the synthesis of 2D metal-organic frameworks (2D MOFs), which can be functionalized in different ways and thus represent a flexible and versatile alternative [10]. The large horizontal and ultrathin dimensions of 2D MOFs lead to very high values of specific surface, atomic surface ratio and number of active places exposed to surface, which can enhance some capabilities 
when compared to bulky materials [11,12]. There are already many examples of $2 \mathrm{D}$ MOFs, usually relying on polytopic planar ligands or molecules that afford a coordination network in two dimensions with a suitable linker $[13,14]$.

The study of magnetic MOFs based on transition metal (3d) and lanthanide (4f) ions is of particular interest. Different types of magnetic MOFs are being investigated [15], such as materials with magnetic cooperativity, spin-crossover [16], magnetocaloric effect [17], and MOFs with slow magnetic relaxation [18], where the nodes are either single-ion magnets (SIMs) [18], single-molecule magnets (SMMs) [19], or which embed single-chain magnets (SCMs) [20].

Another interesting possibility concerns the development of multifunctional complexes that incorporate multiple properties such as magnetism and luminescence [21-28] or photochromism $[29,30]$.

The preparation of 2D molecular layers on surfaces is a prerequisite for the development of many applications. Different approaches have been utilized for this purpose, such as the self-assembly of evaporated molecules [31], the grafting of molecules on functionalized surfaces [32,33], and the use of surface-coordinated MOF thin films (SURMOFs) [34]. The use of hard-templates has also been proposed as an interesting strategy for engineering the structure of MOFs onto surfaces, as recently reviewed in [35].

For 2D MOFs formed of neutral Van der Waals nanosheets, exfoliation by sonication in a liquid matrix has been shown to produce nanosheets stable towards aggregation [36], [37]. However, the isolation of high-quality flakes of 2D MOFs in large amounts that can be suitably deposited onto surfaces remains a challenge. The preparation of high-quality crystalline layers with lateral sizes of $8 \mu \mathrm{m}$ and thicknesses of $4 \mathrm{~nm}$ of a whole family of Fe-based magnetic MOFs, through a liquid exfoliation procedure was recently presented by Coronado et al. [38].

In a recent work, we presented a facile, microwave-assisted method for the preparation of a dysprosium carboxylate-based 2D MOF material, that could be exfoliated into nanosheets by sonication [39].

Herein, we used this microwave-assisted method to synthesize the terbium 2D MOF analogue, of formula $\left[\mathrm{Tb}(\mathrm{MeCOO})(\mathrm{PhCOO})_{2}\right](\mathbf{1})$, formed by the stacking of neutral nanosheets held together only by Van der Waals interactions. The material can be exfoliated by sonication and deposited onto different substrates by spin-coating. We report the luminescent and magnetic properties of $\mathbf{1}$ in the form of flakes deposited onto silicon wafers, compared to those of the bulk counterpart.

\section{Results}

\subsection{Synthesis and Crystal Structure}

The synthesis of $\left[\mathrm{Tb}(\mathrm{MeCOO})(\mathrm{PhCOO})_{2}\right]_{n}(\mathbf{1})$ takes place in a microwave reactor. A microwave pulse applied to the reagents in 1:1 MeOH:MeCN heats the reaction mixture homogenously and favors one intermediate reaction, thus leading to a pure product. After $10 \mathrm{~min}$, the reaction mixture is cooled down and a small amount of solid is obtained. This precipitate is $\left[\mathrm{Tb}(\mathrm{MeCOO})(\mathrm{PhCOO})_{2}\right](\mathbf{1})$. The solid is then separated and the solution is left in a laboratory oven at $40^{\circ} \mathrm{C}$ for one to two weeks; after this time, colorless crystals of 1 can be filtered. At room temperature, larger crystals but in smaller quantities are obtained within similar periods of time. The crystal structure of $\mathbf{1}$ is obtained using synchrotron radiation due to the very small size of the crystals. Table 1 shows the crystallographic parameters for 1. 
Table 1. Single crystal X-ray diffraction data for compound 1.

\begin{tabular}{cc}
\hline Formula & {$\left[\mathrm{Tb}(\mathrm{MeCOO})(\mathrm{PhCOO})_{2}\right](\mathbf{1})$} \\
CCDC & 2095560 \\
Crystal System & Monoclinic \\
Space Group & $\mathrm{P} 2_{1} / \mathrm{c}$ \\
$\mathbf{Z}$ & 4 \\
$\mathbf{a}(\AA)$ & $16.3617(9)$ \\
$\mathbf{b}(\AA)$ & $12.6659(7)$ \\
$\mathbf{c}(\AA)$ & $7.2496(4)$ \\
Alfa & 90 \\
Beta $^{\mathbf{o}}$ & $101.073(2)$ \\
Gamma $^{\mathbf{o}}$ & 90 \\
$\mathbf{V}\left(\AA^{3}\right)$ & $1474.41(14)$ \\
$\mathbf{T}_{\mathbf{3}} \mathbf{( K )}$ & $100(2)$ \\
$\mathbf{X - r a y}$ & $\mathrm{ALS}$ \\
$\mathbf{R}(\mathbf{w R})$ & $0.0258(0.0563)$ \\
\hline
\end{tabular}

Figure 1 shows the asymmetric unit of compound $\mathbf{1}$ and the crystal packing. Compound $\mathbf{1}$ is isostructural to the $\mathrm{Ln}=\mathrm{Dy}$ compound earlier described [39]. The $\mathrm{Tb}(\mathrm{III})$ ion has coordination number 8 , with a distorted square antiprism coordination environment like the Dy analogue. The crystal structure consists of Van der Waals stacked nanosheets of 2D MOFs of formula $\left[\mathrm{Tb}(\mathrm{MeCOO})(\mathrm{PhCOO})_{2}\right]_{n}$, as shown in Figure $1 \mathrm{~b}$.
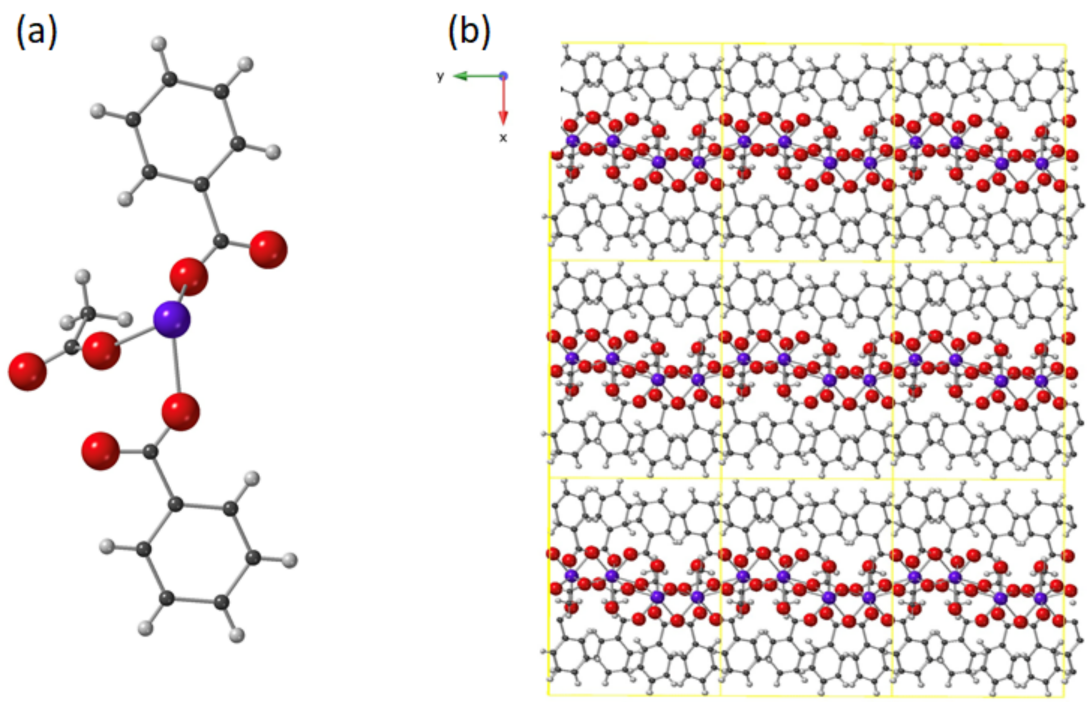

Figure 1. (a) Asymmetric unit of $\mathbf{1},\left[\mathrm{Tb}(\mathrm{MeCOO})(\mathrm{PhCOO})_{2}\right]$, and (b) crystal packing showing three Van der Waals stacked layers of $\mathbf{1}$. Unit cell shown in yellow. Tb: purple; Oxygen: red; Carbon: dark grey; H: light grey.

Figure 2a shows a SEM image of a bulk microcrystalline sample of $\mathbf{1}$. Powder X-ray diffraction (PXRD) confirmed this bulk material is formed of microcrystals of $\mathbf{1}$.

The presented material is composed of neutral 2D layers separated by weak Van der Waals interactions, and thus is ideal for exfoliation. In the past, several examples of coordination networks in two dimensions had been reported, usually relying on polytopic planar ligands or molecules $[13,14,40]$. However, in many cases, these 2D MOFs were formed of charged layers with the counterions in the lamellar space [41], which made them brittle and difficult to exfoliate. For exfoliation, neutral 2D MOFs, organized in three dimensions by weak Van der Waals forces are preferred, as the non-covalent bonding between layers allow the exfoliation without disturbing the bonding within the layer. We have calculated for the previously reported Dy analogue that the interaction energy between two interacting monolayers of the size of a unit cell is $-113 \mathrm{~kJ} / \mathrm{mol}$ (for comparison, the 
interaction energies of two-layer graphene and graphane, with the same surface size as our $2 \mathrm{D} \mathrm{MOF}$, are -274 and $-97 \mathrm{~kJ} / \mathrm{mol}$, respectively) [39].

(a)

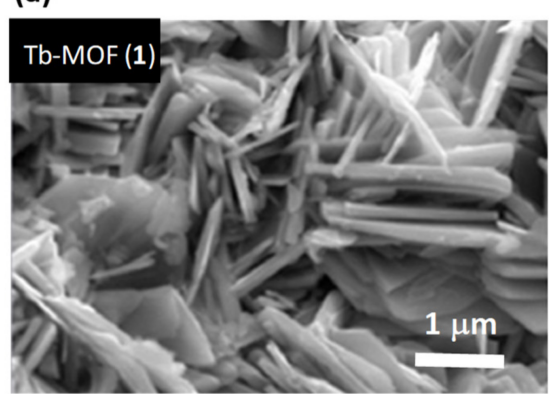

(b)

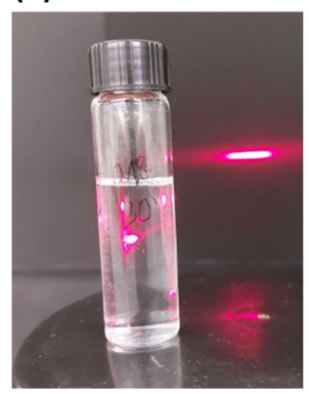

(c)

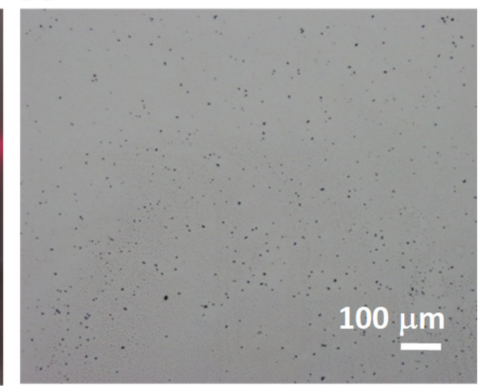

Figure 2. Exfoliation process from (1). (a) SEM image of crystals of $\mathbf{1}$ (bulk), (b) Tindall effect of a suspension of delaminated $\mathbf{1}$, (c) flakes of $\mathbf{1}$ deposited onto a silicon wafer.

\subsection{Exfoliation and Deposition of Tb-2D MOF Flakes onto Silicon}

Exfoliation of 1 into stable nanosheets was carried out by sonication of $1 \mathrm{mg}$ of microcrystals in $5 \mathrm{~mL}$ of $i$-propanol. The mixture was sonicated in a VWR sonicator bath for $1 \mathrm{~h}$ at $30^{\circ} \mathrm{C}$. After this time, the dispersion was centrifuged at $4500 \mathrm{rpm}$ for $10 \mathrm{~min}$ and the colorless dispersion of nanosheets decanted from the remaining white solid. The suspension of delaminated $\mathbf{1}$ produced the Tyndall effect (Figure 2b): when irradiating the colloidal solution of nanosheets the straight trajectory of the red laser is scattered in different directions. The $\mathrm{iPrOH}$ solution of nanosheets was stable for several months. Figure 3 shows TEM images of separate nanosheets of $\mathbf{1}$ deposited on a carbon $\mathrm{Cu}$ grid from the isopropanol solution. The nanosheets of $\mathbf{1}$ break easily upon sonication. Experiments are now being performed to obtain larger intact nanosheets using a shaker instead of ultrasounds. TEM shows that the nanosheets of $\mathbf{1}$ are broken, and form flakes of several nanosheets. In similar exfoliation conditions, for the Dy analogue, we were able to observe isolated nanosheets in TEM, as we reported [39].
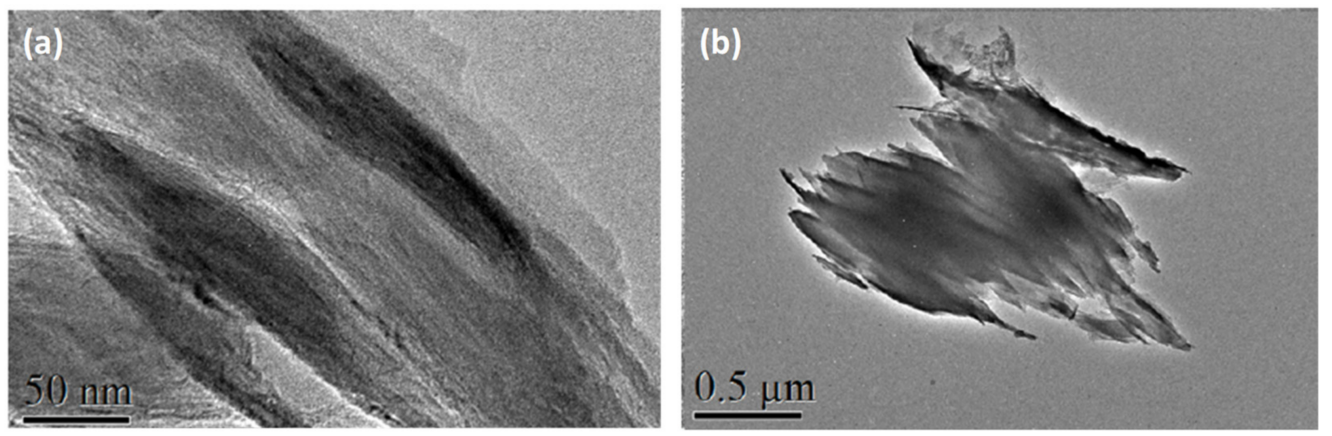

Figure 3. TEM images of exfoliated nanosheets on a carbon-copper grid.

The deposition of the exfoliated material onto a surface is a pre-requisite for further manipulation of the material and its application onto devices. Flakes of $\mathbf{1}$ material were deposited on a $5 \times 5 \mathrm{~mm}^{2}$ silicon wafer by two methods: drop-casting and spin-coating. Different drop-casting experiments were performed, changing the number of droplets and volume of liquid. This method produced a non-homogeneous distribution of flakes in the center of the sample (see Figure 4a) and was, therefore, abandoned. In contrast, a uniform distribution of flakes was achieved by spin-coating (Figure $4 \mathrm{~b}$ ). Different experiments were performed by changing the drop volume, multiple deposition of drops, and rotation speed. The surface coverage was observed under an optical microscope and quantified with Mountains software (Figure 4c). Figure 4e summarizes the results of spin-coating experiments. A maximum coverage of $\sim 8 \%$ could be achieved under optimized conditions. 
The histogram distribution of flake sizes shows that the average flake diameter is ca. $5 \mu \mathrm{m}$ (Figure $4 \mathrm{~d}$ ).

(a)
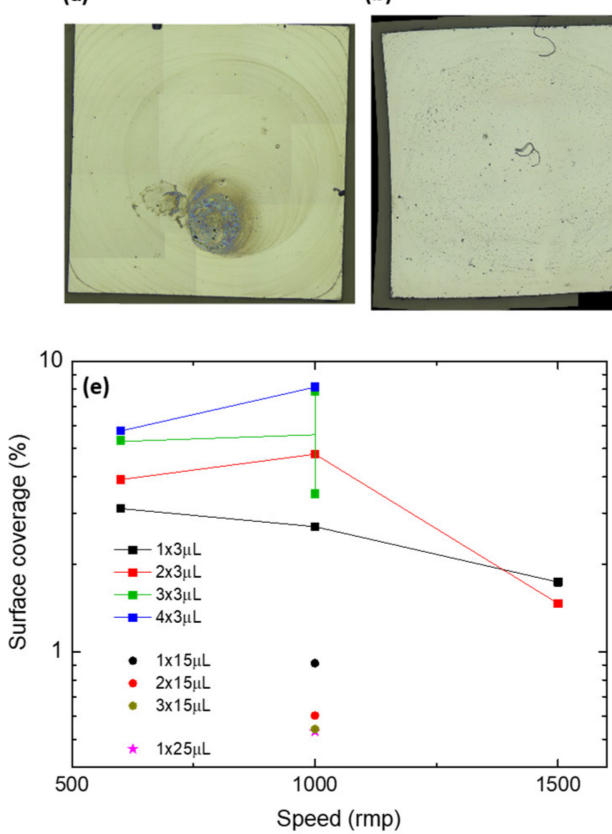

(b) (c)
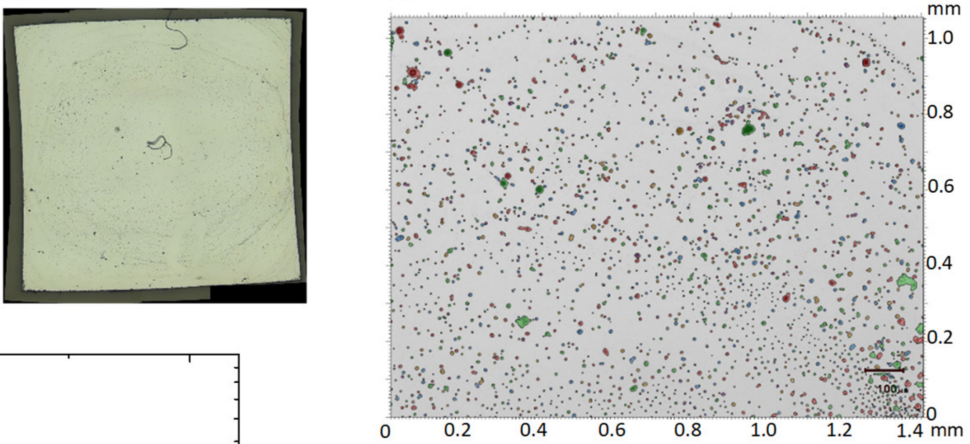

(d)

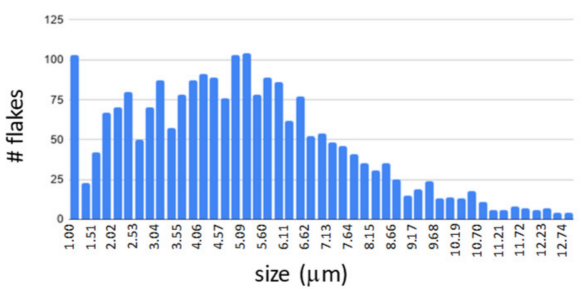

Figure 4. Optical image of $5 \times 5 \mathrm{~mm}^{2}$ silicon wafer with deposited Tb-MOF flakes, by drop-casting (a) and spin-coating (b); (c) quantification of surface coverage and (d) distribution of flake sizes, for a spin-coated sample; (e) surface coverage determined for different spin-coating conditions.

Figure 5a shows a SEM image of one of the deposited flakes on silicon. Energy dispersive X-ray spectroscopy (EDS) analysis on the flake confirms the presence of $\mathrm{Tb}$ (Figure $5 b$ ).
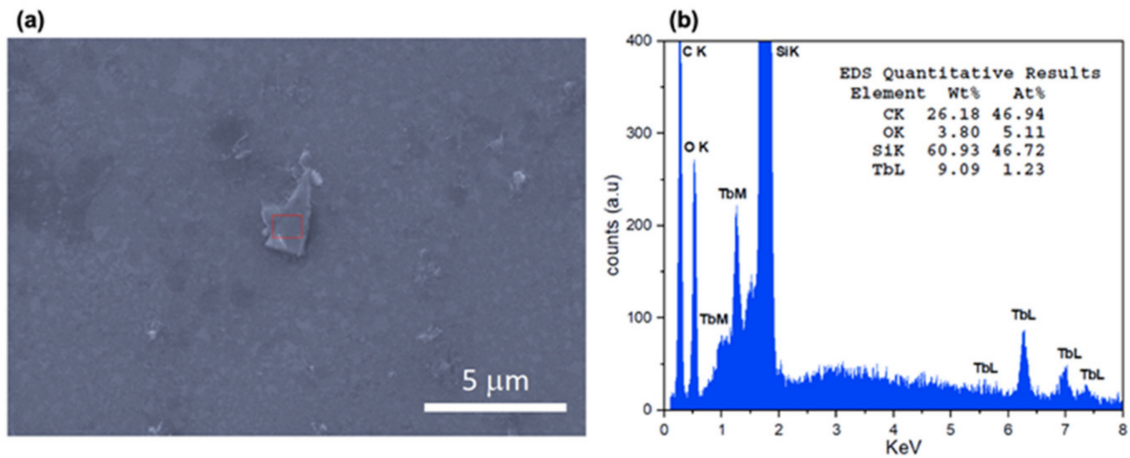

Figure 5. SEM image of a Tb-2D MOF flake deposited on silicon (a), and EDS analysis (b).

\subsection{Luminescence and Raman Spectroscopy}

First, the luminescent properties of $\mathbf{1}$ as bulk microcrystalline powder were characterized. When exposed to UV radiation the sample emitted green visible light (Figure 6a). The excitation spectrum, monitored at $544 \mathrm{~nm}$, showed a broad band arising from the benzoate ligands at around $280 \mathrm{~nm}$ (Figure 6b); therefore, this wavelength was chosen for ulterior emission studies upon ligand excitation. 
(b)

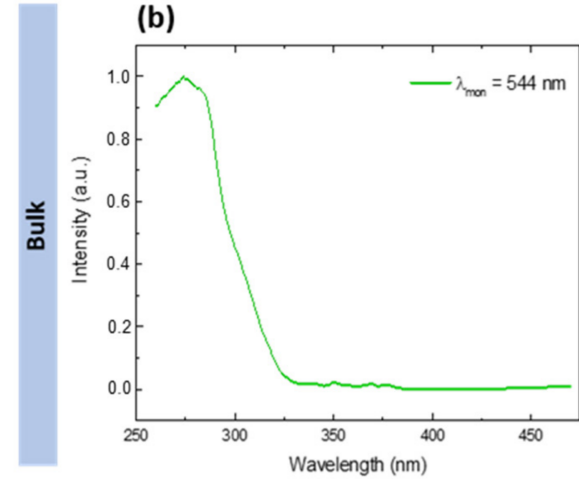

(e)

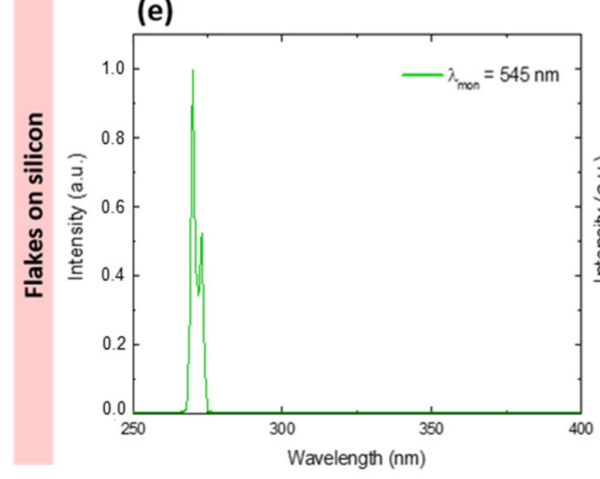

(c)

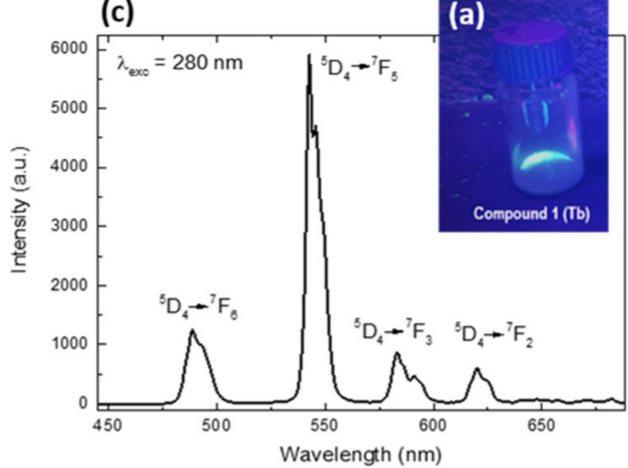

(f)

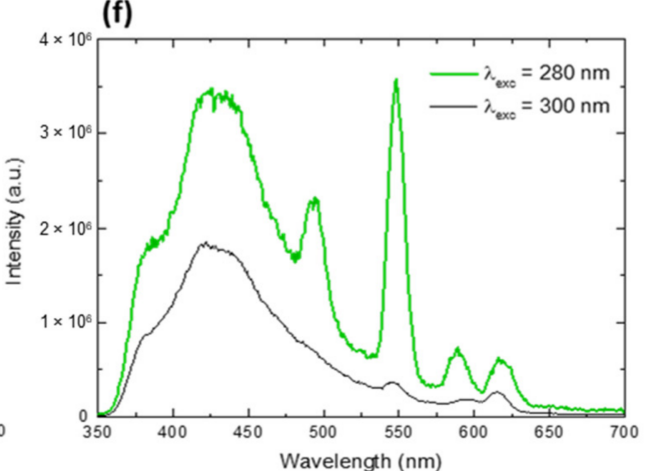

(d)

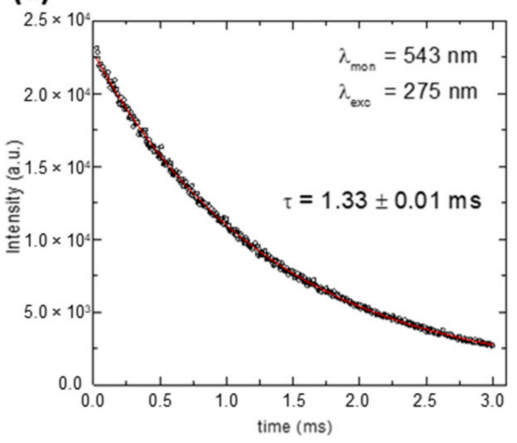

Figure 6. Top: luminescence of $\mathbf{1}$ in bulk: (a) Emission of powder under UV lamp, (b) excitation spectra monitored at $\lambda_{\text {mon }}=544 \mathrm{~nm}$, (c) emission spectra upon ligand excitation at $\lambda_{\text {exc }}=280 \mathrm{~nm},(d)$ lifetime measurement at $\lambda_{\mathrm{exc}}=280 \mathrm{~nm}$, monitoring the decay of the $544 \mathrm{~nm}$ peak, and fit to a single-logarithmic decay, with $\tau=1.33 \mathrm{~ms}$. Bottom: luminescence of flakes of $\mathbf{1}$ deposited on silicon: (e) excitation and (f) emission spectra.

The emission spectrum of microcrystalline 1 exhibits four characteristic bands at 488 , 546,590 and $616 \mathrm{~nm}$ when excited at $\lambda_{\text {exc }}=280 \mathrm{~nm}$. These correspond to the ${ }^{5} D_{4} \rightarrow{ }^{7} F_{J}$ $(\mathrm{J}=6,5,4,3)$ transitions to the ground state multiplet of the $\mathrm{Tb}(\mathrm{III})$ ion (Figure $6 \mathrm{c}$ ), dominated by the ${ }^{5} D_{4} \rightarrow{ }^{7} F_{5}$ transition at $546 \mathrm{~nm}$. The luminescence decay of this peak was $\tau_{\text {obs }}=1.33 \pm 0.01 \mathrm{~ms}$ (Figure $6 \mathrm{~d}$ ). The overall quantum yield upon excitation at $280 \mathrm{~nm}$ was found to be sizeable, $Q_{T b}^{\text {ligand }}=61 \pm 1 \%$.

The excitation and emission spectra for the flakes deposited on silicon are shown in Figure $6 \mathrm{e}, \mathrm{f}$, respectively. The emission spectrum recorded at $\lambda_{\mathrm{exc}}=280 \mathrm{~nm}$ exhibits a broad band at low wavelengths, that stems from the silicon wafer reflection (indeed, the emission spectrum recorded for a pristine wafer presented the same band). However, above this background the characteristic ${ }^{5} D_{4} \rightarrow{ }^{7} F_{J}$ emission peaks of $\mathrm{Tb}(\mathrm{III})$ are clearly observed (Figure 6f).

In addition, micro-Raman spectroscopy was used in order to probe the vibrational modes of Tb-MOF flakes. The setup was provided with a microscope allowing to focus the incident blue laser beam ( $448 \mathrm{~nm}$ ) of power $0.15 \mathrm{~mW}$ onto individual flakes. The Raman shift spectra in the vibrational mode region (500-1745 $\mathrm{cm}^{-1}$ ) only exhibited the typical Raman peaks at $521 \mathrm{~cm}^{-1}$ and $965 \mathrm{~cm}^{-1}$ associated to the silicon wafer [42], as shown in Figure 7a. No other vibrational peaks associated with the flakes' material could be distinguished, as the signal was dominated by the stronger tails of the Tb luminescence peaks in this experimental window. 
(b)
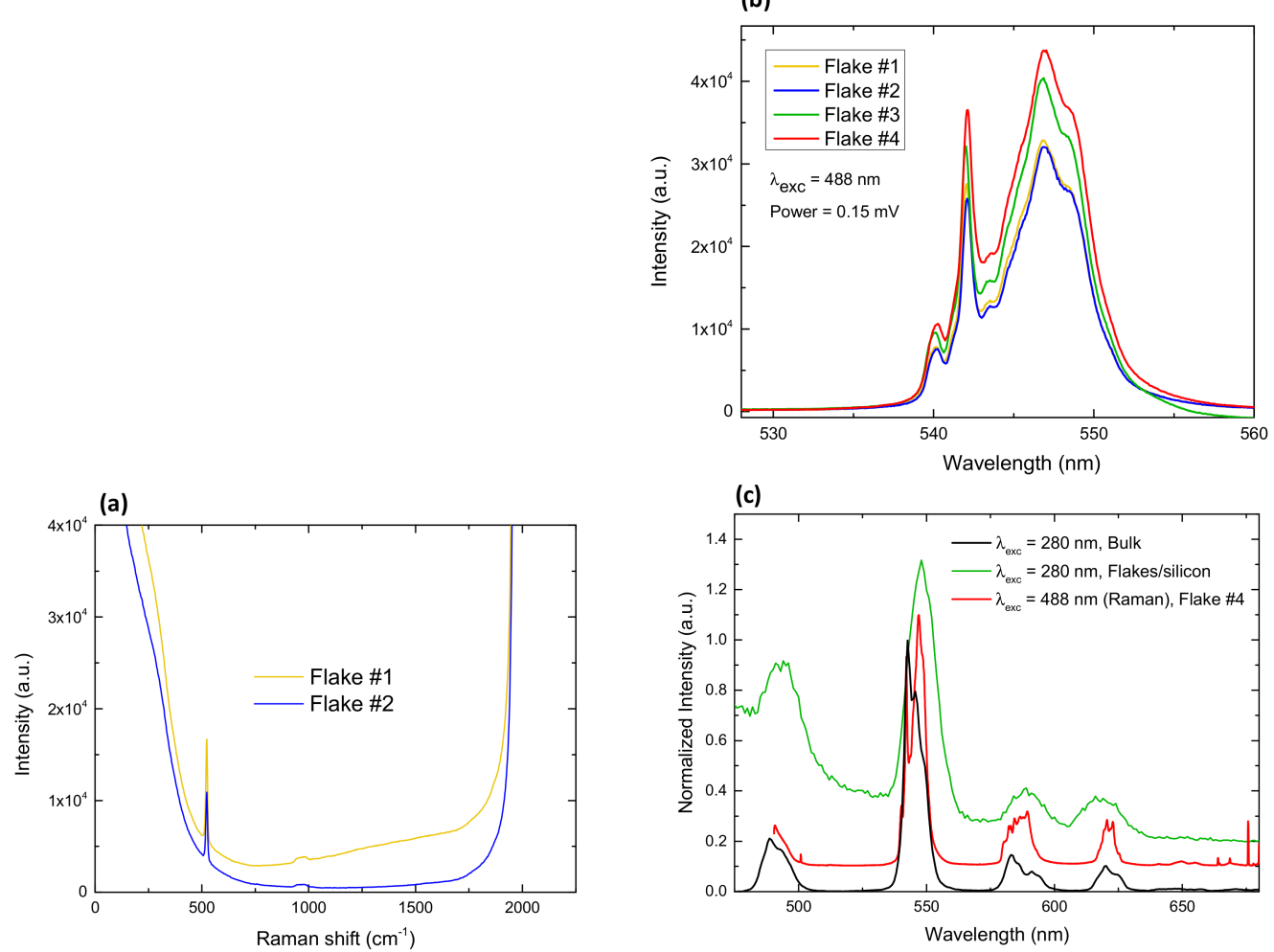

Figure 7. Raman spectroscopy of Tb-2D MOF flakes on silicon. (a) Raman shift spectra, relative to laser wavelength $(488 \mathrm{~nm})$ measured on two different flakes; (b) Tb emission spectrum peak measured on 4 different flakes, (c) Emission spectra obtained in Raman set up ( $\left.\lambda_{\text {exc }}=488 \mathrm{~nm}\right)$ from a single flake/silicon (red line) and of flakes on top of a Si waver upon ligand excitation, $280 \mathrm{~nm}$ (green line). Emission from bulk sample (black line). Spectra have been vertically shifted for the sake of comparison.

Interestingly, the spatial resolution of our Raman setup allowed us to measure the luminescence spectra of individual flakes upon excitation at $\lambda_{\text {exc }}=488 \mathrm{~nm}$ (the laser wavelength). Figure $7 \mathrm{~b}$ shows the $546 \mathrm{~nm}-\mathrm{Tb}$ peak measured at four different flakes. The observed fine structure was very reproducible from one flake to another. Changes in the intensity of the peaks may be associated with the different thicknesses of the deposited flakes, or slight differences in the focusing. Figure 7c shows the full emission spectra recorded between $490-681 \mathrm{~nm}$ at one of the flakes. The position of the main peaks measured by Raman (red line) coincides with those measured by fluorimetry for the flakes-on-silicon (green line) and the bulk (black line), upon ligand excitation $(280 \mathrm{~nm})$. However, the emission spectrum obtained in the Raman set up shows further fine structure, due to the higher spectral resolution attained in the Raman system.

\subsection{Magnetic Characterization}

The magnetization as a function of the applied field for a powdered sample of (1) is shown in Figure 8a. The $M(H)$ curve measured at $T=1.8 \mathrm{~K}$ reaches for high fields, $\mu_{0} H=5 \mathrm{~T}$, the expected saturation value for an angular random distribution of highly uniaxial anisotropic grains, $M_{\text {sat }}{ }^{\text {powder }}=0.5 g_{\mathrm{z}}{ }^{*} S_{\mathrm{z}}^{*}=4.5 \mu_{\mathrm{B}} /$ f.u., where $g_{\mathrm{z}}{ }^{*}=18$ is the $\mathrm{z}$ component of the gyromagnetic tensor for $\mathrm{Tb}$ within a $\mathrm{S}_{\mathrm{z}}^{*}=1 / 2$ effective spin description. The magnetic susceptibility was investigated under $1 \mathrm{kOe}$ in the range of $1.8-300 \mathrm{~K}$ and is shown as $\chi T(T)$ plot in Figure $8 \mathrm{~b}$. The $\chi T$ value at $300 \mathrm{~K}$ for $\mathbf{1}(11.16 \mathrm{emu} \mathrm{K} / \mathrm{mol})$ is slightly below the expected free-ion $\mathrm{Tb}^{3+}$ value. Upon cooling, $\chi T$ decreases until reaching a plateau of $9.1 \mathrm{emu} \mathrm{K} / \mathrm{mol}$ at $10 \mathrm{~K}$, then decreases abruptly to a minimum value of $8.1 \mathrm{emu} \mathrm{K} / \mathrm{mol}$ at $2.0 \mathrm{~K}$, while an upturn in $\chi T$ is hinted at lower temperatures (Figure $8 \mathrm{~b}$, inset). That decrease can be explained by the depopulation of the Tb crystal field (CF) split 
levels and the presence of AF interactions. The Curie-Weiss equation, $\chi=C /(T-\theta)$, was used to fit the $1 / \chi(T)$ data, yielding $C=11.29 \pm 0.07 \mathrm{emu} \mathrm{K} / \mathrm{mol}$ and $\theta=-4.83 \pm 0.01 \mathrm{~K}$ for 1 . The negative $\theta$ values indicate the existence of predominant antiferromagnetic (AF) dipolar interactions between the $\mathrm{Tb}$ ions. The magnetic behavior of the Tb-MOF compound qualitatively resembles that of the Dy-2D MOF analogue, previously reported [39], where all dipolar interactions between each Dy ion with its first neighbors were found to be AF. Although, the $\chi T$ upturn, indicating the existence of competing ferromagnetic (FM) interactions at low temperatures, is less prominent in the former.

(a)

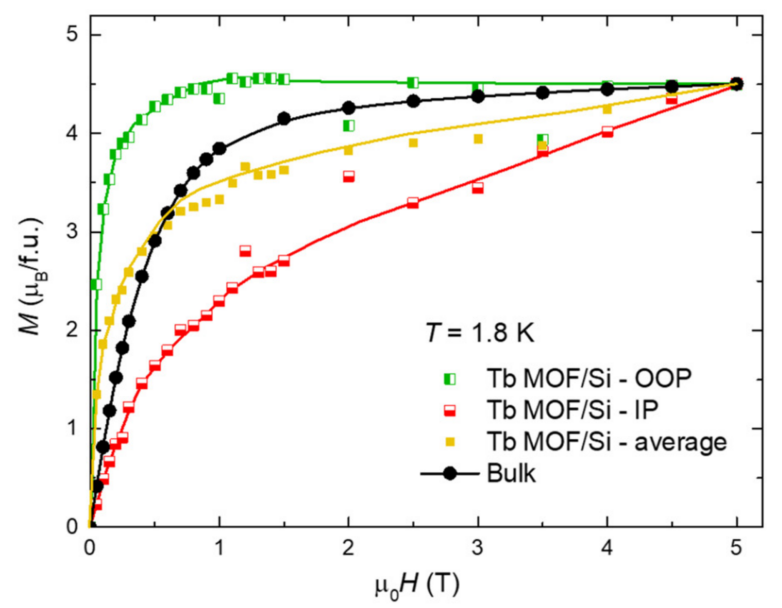

(b)

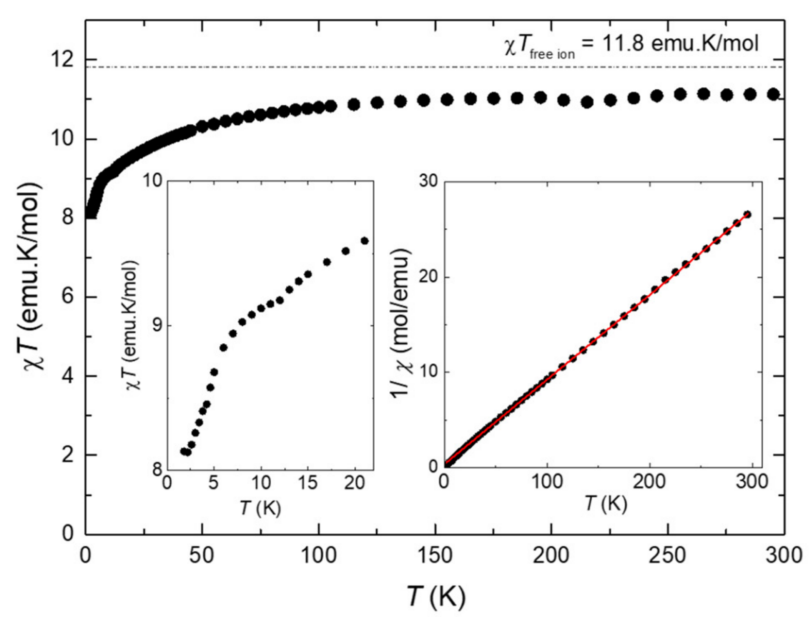

Figure 8. SQUID magnetic characterization of Tb-2D MOF of (1). (a) Field-dependence of the magnetization at $T=1.8 \mathrm{~K}$ for the bulk material, and flakes deposited on silicon, with the field applied in-plane (IP) and out-of-plane (OOP) with respect to the substrate, (b) temperature dependence of the susceptibility-temperature product, at $H=1 \mathrm{kOe}$, for the bulk. Inset: detail of the $\chi T(T)$ curve at low-T; also, $1 / \chi$ curve and fit to a Curie-Weiss law.

Static magnetic measurements were in addition performed on flakes deposited on a $5 \times 5 \mathrm{~mm}^{2}$ silicon waver. The flakes' magnetic contribution was obtained after carefully subtracting the substrate and holder contribution, separately measured. Figure 8a shows the $M(H)$ magnetization curves, measured with the magnetic field applied in-plane (IP) and out-of-plane (OOP) with respect to the substrate. Since the absolute mass of the deposited flakes is unknown, the $M(H)$ curve was normalized to match the saturation value of the bulk sample at $5 \mathrm{~T}$. The results reflect the magnetic anisotropy of the nanosheets. The $M(H)$ curve with the field OOP lies above the IP $M(H)$ curve. The averaged curve, $\left(M_{\mathrm{IP}}+M_{\mathrm{OOP}}\right) / 2$, is close to the magnetization curve for the bulk, within the experimental uncertainty.

On the other hand, the experimental determination of the $\chi T(T)$ for the deposited flakes was not possible, as their signal at high temperatures became too small compared to the substrate to allow a reliable substrate subtraction.

Alternating-current (ac) susceptibility measurements as a function of frequency $(0.1-1 \mathrm{kHz})$, temperature $(T=1.8-8 \mathrm{~K})$ and field $(H=0-30 \mathrm{kOe})$, were performed to characterize the relaxation properties of $\mathbf{1}$ in the bulk. The complex did not show frequency dependent out-of-phase $\chi$ " signal under $H=0$. Upon application of a dc field, quantum tunneling of the magnetization (QTM) was effectively suppressed and slow relaxation of the magnetization effects was observed. The $\chi^{\prime \prime}(f, T)$ curves at optimum field $H=3 \mathrm{kOe}$, and $\chi^{\prime \prime}(f, H)$ data at $T=2 \mathrm{~K}$ are shown in Figure 9a,b. From the position of the $\chi^{\prime \prime}$ peaks, the relaxation time as a function of the inverse temperature and the magnetic field were determined (Figure 9c,d). 

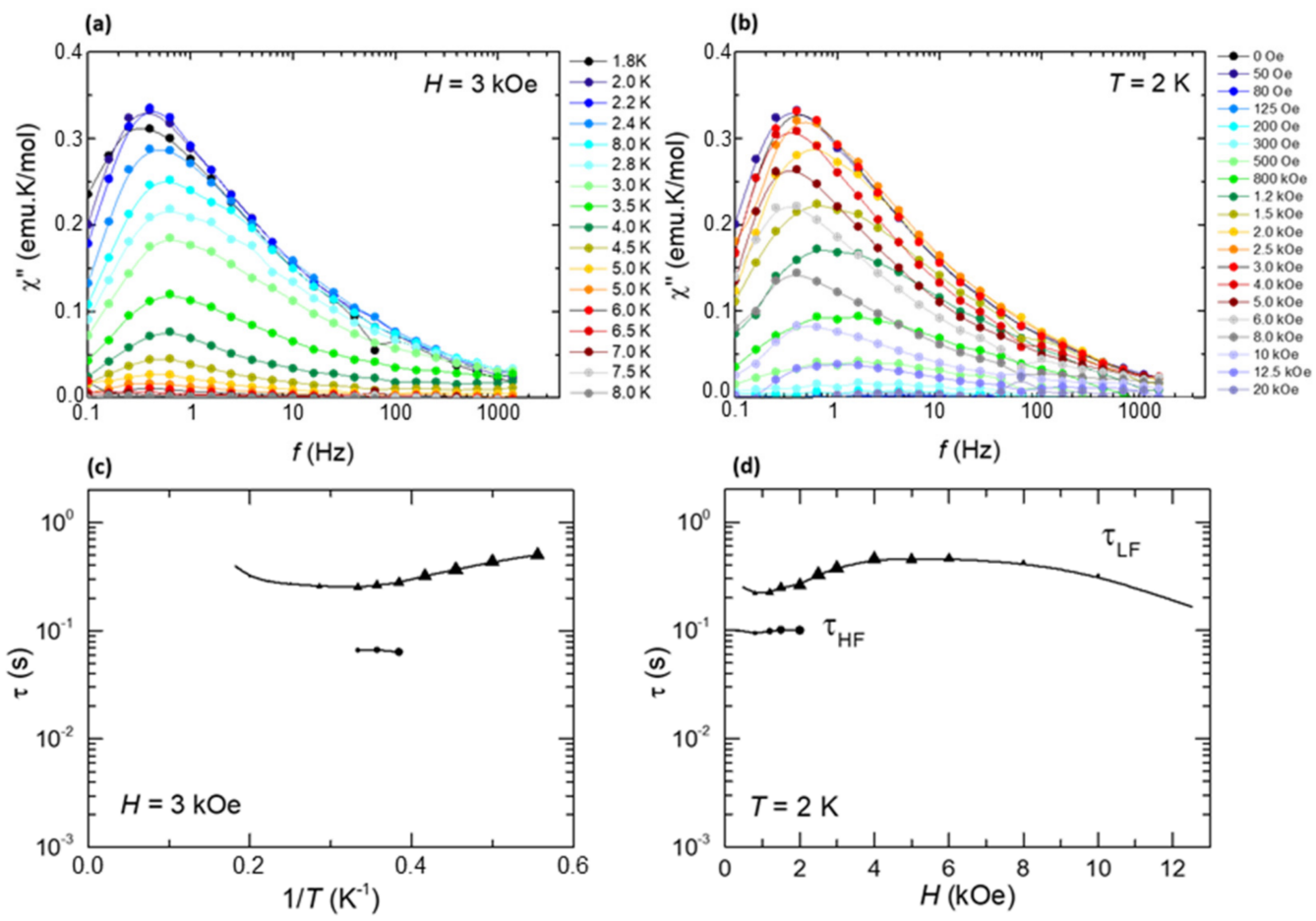

Figure 9. Top: out-of-phase component of the ac susceptibility as a function of the frequency, (a) at constant field $H=3 \mathrm{kOe}$ and different temperatures, (b) at constant temperature $T=2 \mathrm{~K}$ and different applied fields for a powdered sample of (1). Bottom: magnetic relaxation time, (c) as a function of the inverse of the temperature, $\tau(1 / T)$, at $H=3 \mathrm{kOe}$, and (d) as a function of the applied magnetic field, $\tau(H)$, at $T=2 \mathrm{~K}$.

The intense peak $\chi$ " measured at low frequencies, shows relaxation time dependencies, $\tau_{\mathrm{LF}}(1 / T)$ and $\tau_{\mathrm{LF}}(H)$, typical of a direct process mechanism affected by bottleneck. A second relaxational process is hinted at as a bump at higher frequencies; however, too few data are available to deduce the associated relaxation mechanism. Unlike in the Dy-2D MOF analogue [39], no clear thermally-activated process could be observed.

\section{Experimental Methods}

$\left[\mathrm{Tb}(\mathrm{MeCOO})(\mathrm{PhCOO})_{2}\right](\mathbf{1})$ : the synthesis of $\left[\mathrm{Tb}(\mathrm{MeCOO})(\mathrm{PhCOO})_{2}\right](\mathbf{1})$ followed the procedure described in [39]. All chemicals and solvents were purchased from commercial sources and used as received. An amount of $0.0883 \mathrm{~g}$ of hydrated $\mathrm{Tb}(\mathrm{MeCOO})_{3} \cdot \mathrm{xH}_{2} \mathrm{O}$ $(0.26 \mathrm{mmol})$ and $0.063 \mathrm{~g}$ of $\mathrm{PhCOOH}(0.52 \mathrm{mmol})$ were placed in a CEM Discover Microwave Reactor with $4 \mathrm{~mL}$ of a MeOH:MeCN 1:1 mixture. A pulse of $150 \mathrm{~W}$ was applied and the reaction kept for $10 \mathrm{~min}$ at a maximum temperature of $125^{\circ} \mathrm{C}$. The reaction was cooled to room temperature and a colorless precipitate was filtered off. The solution was left for 9 days at $40{ }^{\circ} \mathrm{C}$; after this time colorless crystals of $\mathbf{1}$ were obtained in $37 \%$ yield. The precipitate is analyzed by infrared (IR) and powder X-ray diffraction (PXRD) and found to be the same material. Total yield: $55 \%$. Elemental analyses for $\mathbf{1} \cdot \mathrm{H}_{2} \mathrm{O}$ calculated (experimental): C 40.44 (40.79)\%; H 2.55 (2.96)\%. IR data $\left(\mathrm{cm}^{-1}\right)$ : $3069(\mathrm{w}), 3039(\mathrm{w})$, $3023(\mathrm{w}), 1590(\mathrm{~s}), 1536(\mathrm{~s}), 1436(\mathrm{w}), 1394(\mathrm{~s}), 1331(\mathrm{~s}), 1248(\mathrm{~m}), 1164(\mathrm{~s}), 1068(\mathrm{w}), 1022(\mathrm{w})$, $993(\mathrm{~m}), 930(\mathrm{~m}), 868(\mathrm{w})$, 10.1002/anie. $847(\mathrm{w}), 830(\mathrm{w}), 788(\mathrm{~m}), 709(\mathrm{~s}), 700(\mathrm{~s}), 687(\mathrm{~s})$, $667(\mathrm{~s}), 617(\mathrm{w}), 604(\mathrm{w})$.

Exfoliation: $1 \mathrm{mg}$ of $\mathbf{1}$ is placed in a vial with $5 \mathrm{~mL}$ of $i-\mathrm{PrOH}$. The tube is placed in a VWR sonicator at $45 \mathrm{KHz}$ and $120 \mathrm{~W}$ with a water bath at $30^{\circ} \mathrm{C}$ for $1 \mathrm{~h}$. The remaining solid is separated by decantation after centrifugation $(4500 \mathrm{rpm}, 10 \mathrm{~min})$ to separate the suspension of nanosheets. The dispersion of nanosheets displays Tyndall effect and is stable for at least 3 months. 
X-ray diffraction data for 1 were collected with a Bruker APEXII SMART diffractometer using a Molybdenum K-alfa microfocus radiation source (lambda $=0.71073 \AA$ ) at GMMF, and only a unit cell was obtained. Samples were taken to synchrotron source Advanced Light Source, beamline 12.2.1 (Berkeley, CA, USA) and collected using shutterless phi and omega scans on a Bruker D8 with PHOTON II detector at $0.7288 \mathrm{~nm}$. The structures were solved by Patterson or intrinsic phasing methods (SHELXS2013 and SHELXT) and refined on $\mathrm{F}_{2}$ (SHELXL-2016). Hydrogen atoms were included on calculated positions, riding on their carrier atoms. Powder X-ray diffraction data for $\mathbf{1}$ (precipitate), and $\mathbf{1}$ (crystals) were collected at the Centres Cientifics $i$ Tecnologics-Universitat de Barcelona (CCiTUB).

Crystal data and some further details concerning x-ray analysis are given in Table 1. The bond lengths and angles for 1 are listed in CCDC-2095560. These data can be obtained free of charge via www.ccdc.cam.ac.uk / conts / retrieving.html (or from the Cambridge Crystallographic Data Centre, 12 Union Road, Cambridge CB2 1EZ, UK; fax: (+44) 1223-336-033; ordeposit@ccdc.ca.ac.uk).

Scanning Electron Microscopy (SEM): the bulk specimen was coated in graphite and analyzed on the CCiTUB facilities. SEM images and EDS of flakes deposited onto silicon were taken without $C$ coating at ICMAB facilities.

Static magnetic measurements: magnetization, $M(H)$, and susceptibility, $\chi(T)$, data from powdered polycrystalline samples were measured with the addition of Daphne oil to avoid grain orientation, in a Quantum Design SQUID Magnetometer equipped at Universidad de Zaragoza with the RSO option and a Quantum Design PPMS with the VSM option. $M(H)$ was measured at $T=1.8 \mathrm{~K}$ up to $140 \mathrm{kOe}$ and $\chi(T)$ from 1.8 to $300 \mathrm{~K}$, with an applied field of $1 \mathrm{kOe}$.

Dynamic magnetic measurements for polycrystalline samples were conducted at fixed temperatures in the range $1.8<T<6 \mathrm{~K}$, with an excitation field of $4 \mathrm{Oe}$, at dc bias fields in the range $0<H<50 \mathrm{kOe}$, while sweeping the frequency $0.1<f<1000 \mathrm{~Hz}$ in the same SQUID magnetometer.

$M(H)$ at $1.8 \mathrm{~K}$ from $0-5 \mathrm{~T}$, and $\chi(T)$ at $1 \mathrm{kOe}$ from $1.8-300 \mathrm{~K}$ curves of flakes deposited onto $5 \times 5 \mathrm{~mm}^{2}$ silicon wafers, with the field $H$ applied IP and OOP with respect to the substrate, were measured in a SQUID magnetometer (MPMS3 from Quantum Design) in DC scan at ICMAB. The pristine substrate was measured, with the field applied in the two directions, so as to subtract the diamagnetic contribution.

Photoluminescence emission and excitation spectra of $\mathbf{1}$ (bulk) were measured using a Fluorolog FL-1057 Jobin Ybon HORIBA spectrofluorometer. Phosphorescence lifetimes were recorded with a Fluoromax phosphorimeter accessory containing a UV xenon flash tube. Quantum yield (QY) was measured using a Hamamatsu Absolute PL Quantum Yield spectrometer C11347 (Hamamatsu Quantaurus QY). The absolute QY (ratio of the number of photons emitted by photoluminescence to the number of photons absorbed by the light-emitting material) was measured using an integrating sphere. Powdered samples were placed in a capillary with an internal diameter of $1 \mathrm{~mm}$. The absorption and emission spectra of the sample container (the blank) were separately recorded. The QY was calculated as: $Q=\left(E_{c}-E_{a}\right) /\left(L_{a}-L_{c}\right)$ with $E_{\mathrm{c}}$ being the integrated emission spectrum of the sample, $E_{\mathrm{a}}$ being the integrated blank emission spectrum, $L_{\mathrm{a}}$ being the blank absorption, and $L_{\mathrm{c}}$ being the sample adsorption at the excitation wavelength.

Luminescence studies of flakes of $\mathbf{1}$ on silicon wafers were measured using the spectrofluorometer NanologTM-Horiba Jobyn Yvon fluorimeter at the Inorganic Chemistry Section, UB. The excitation and emission spectra of the deposited flakes on a silicon wafer were measured in the fluorimeter in a "Right Angle" configuration, i.e., with the incident and sensed beams forming $90^{\circ}$, and the incident light impinging the sample at $45^{\circ}$.

Raman scattering experiments were performed at room temperature in the backscattering geometry using a T64000 Horiba Jobin-Yvon micro-Raman spectrometer equipped with a high sensitivity liquid nitrogen cooled CCD (charge-coupled device) as the detector, and an Olympus BX40 microscope. The $488 \mathrm{~nm}$ laser line was used for the measurements. Samples were mounted on the rotation X-Y stage of the microscope [43]. The incident laser 
beam was focused to $\mathrm{a} \approx 1 \mu \mathrm{m}$ spot using a $\times 100$ microscope objective on the sample. The laser power was kept below $0.15 \mathrm{~mW}$ to avoid laser-induced heating and degradation of the analyzed flakes. The spectrometer resolution was $2 \mathrm{~cm}^{-1}$.

\section{Conclusions}

A simple, microwave assisted method was used for the synthesis of a new magnetic and luminescent $\mathrm{Tb}$ 2D-MOF material (1). Compound $\mathbf{1}$ can be easily delaminated in an isopropanol solution by sonication. A uniform distribution of $5 \mu \mathrm{m}$-size flakes, covering up to an $8 \%$ of a $5 \times 5 \mathrm{~mm}^{2}$ silicon substrate could be prepared by spin-coating. The deposited Tb-2D MOF flakes exhibit both luminescence in the visible, and axial magnetic anisotropy. Hence, our method represents a promising approach for the preparation of multifunctional 2D materials on different surfaces, allowing for the development of hybrid materials, multilayer hetero-nanostructures or devices for different applications.

Author Contributions: Conceptualization, E.B. and E.C.S.; methodology, E.B. and E.C.S.; formal analysis, E.B., A.A., S.H., A.P. and E.C.S.; investigation, E.B., A.A., S.H., A.P., N.M., S.F., L.N.-S. and J.G.; resources, P.S., L.N.-S., J.G., N.M., A.A., S.F., A.P., N.S.S. and E.C.S.; data curation, E.B., E.C.S., A.A. and S.H.; writing-original draft preparation, E.B.; visualization, E.B. and E.C.S.; project administration, E.B. and E.C.S.; funding acquisition, E.B., E.C.S. and A.P. All authors have read and agreed to the published version of the manuscript.

Funding: This research was funded by the Spanish Ministry of Economy, Industry and Competitiveness (MINECO, Grant Nos. MAT2017-83468-R; PGC2018-098630-B-I00 (ECS)) and from the regional Government of Aragon (E12-20R RASMIA project).

Institutional Review Board Statement: Not applicable.

Informed Consent Statement: Not applicable.

Data Availability Statement: Not applicable.

Acknowledgments: Authors would like to acknowledge the use of Servicio General de Apoyo a la Investigación-SAI, Universidad de Zaragoza.

Conflicts of Interest: The authors declare no conflict of interest. The funders had no role in the design of the study; in the collection, analyses, or interpretation of data; in the writing of the manuscript, or in the decision to publish the results.

Sample Availability: Samples of the compounds are not available from the authors.

\section{References}

1. Vijayakumar, S.; Nagamuthu, S.; Muralidharan, G. Supercapacitor Studies on NiO Nanoflakes Synthesized Through a Microwave Route. ACS Appl. Mater. Interfaces 2013, 5, 2188-2196. [CrossRef] [PubMed]

2. Mendoza-Sánchez, B.; Gogotsi, Y. Synthesis of Two-Dimensional Materials for Capacitive Energy Storage. Adv. Mater. 2016, 28, 6104-6135. [CrossRef] [PubMed]

3. Cui, H.; Guo, Y.; Ma, W.; Zhou, Z. 2 D Materials for Electrochemical Energy Storage: Design, Preparation, and Application. ChemSusChem 2020, 13, 1155-1171. [CrossRef]

4. Lin, L.; Chen, J.; Liu, D.; Li, X.; Wallace, G.G.; Zhang, S. Engineering 2D Materials: A Viable Pathway for Improved Electrochemical Energy Storage. Adv. Energy Mater. 2020, 10, 2002621. [CrossRef]

5. Heard, C.J.; Cejka, J.; Opanasenko, M.; Nachtigall, P.; Centi, G.; Perathoner, S. 2D Oxide Nanomaterials to Adress the Energy Transition and Catalysis. Adv. Mater. 2018, 31, 1801712. [CrossRef] [PubMed]

6. Xie, Z.; Chen, S.; Duo, Y.; Zhu, Y.; Fan, T.; Zou, Q.; Qu, M.; Lin, Z.; Zhao, J.; Li, Y.; et al. Biocompatible Two- Dimensional Titanium Nanosheets for Multimodal Imaging-Guided Cancer Theranostics. ACS Appl. Mater. Interfaces 2019, 11, 22129-22140. [CrossRef]

7. Navarro-Moratalla, J.O.I.E.; Manãs-Valero, S.; Pinilla-Cienfuegos, E.; Castellanos-Gomez, A.; Quereda, J.; Rubio-Bollinger, G.; Chirolli, L.; Silva-Guillén, J.A.; Agraït, N.; Steele, G.A.; et al. Enhanced superconductivity in atomically thin TaS2. Nat. Commun. 2016, 7, 11043. [CrossRef]

8. Huang, B.; Clark, G.; Navarro-Moratalla, E.; Klein, D.R.; Cheng, R.; Seyler, K.L.; Zhong, D.; Schmidgall, E.; McGuire, M.; Cobden, D.H.; et al. Layer-dependent ferromagnetism in a van der Waals crystal down to the monolayer limit. Nat. Cell Biol. 2017, 546, 270-273. [CrossRef]

9. Miró, P.; Audiffred, M.; Heine, T. An atlas of two-dimensional materials. Chem. Soc. Rev. 2014, 43, 6537-6554. [CrossRef] 
10. Coronado, E. Molecular magnetism: From chemical design to spin control in molecules, materials and devices. Nat. Rev. Mater. 2019, 5, 87-104. [CrossRef]

11. Wang, B.; Jin, J.; Ding, B.; Han, X.; Han, A.; Liu, J. General Approach to Metal-Organic Framework Nanosheets With Controllable Thickness by Using Metal Hydroxides as Precursors. Front. Mater. 2020, 7, 37. [CrossRef]

12. Ding, G.; Wang, Y.; Zhang, G.; Zhou, K.; Zeng, K.; Li, Z.; Zhou, Y.; Zhang, C.; Chen, X.; Han, S.-T. 2D Metal-Organic Framework Nanosheets with Time-Dependent and Multilevel Memristive Switching. Adv. Funct. Mater. 2019, 29, 1806637. [CrossRef]

13. Zhao, M.; Huang, Y.; Peng, Y.; Huang, Z.; Ma, Q.; Zhang, H. Two-dimensional metal-organic framework nanosheets: Synthesis and applications. Chem. Soc. Rev. 2018, 47, 6267-6295. [CrossRef] [PubMed]

14. Yin, D.-D.; Chen, Q.; Meng, Y.-S.; Sun, H.-L.; Zhang, Y.-Q.; Gao, S. Slow magnetic relaxation in a novel carboxylate/oxalate/hydroxyl bridged dysprosium layer. Chem. Sci. 2015, 6, 3095-3101. [CrossRef]

15. Mínguez Espallargas, G.; Coronado, E. Magnetic functionalities in MOFs: From the framework to the pore. Chem. Soc. Rev. 2018, 47, 533-557. [CrossRef] [PubMed]

16. Bartual-Murgui, C.; Akou, A.; Thibault, C.; Molnár, G.; Vieu, C.; Salmon, L.; Bousseksou, A. Spin-crossover metal-organic frameworks: Promising materials for designing gas sensors. J. Mater. Chem. C 2015, 3, 1277-1285. [CrossRef]

17. Guo, F.-S.; Leng, J.-D.; Liu, J.-L.; Meng, Z.-S.; Tong, M.-L. Polynuclear and Polymeric Gadolinium Acetate Derivatives with Large Magnetocaloric Effect. Inorg. Chem. 2012, 51, 405-413. [CrossRef]

18. Baldovi, J.J.; Coronado, E.; Gaita-Arino, A. A SIM-MOF: Three-Dimensional Organisation of Single-Ion Magnets with AnionExchange Capabilities. Chem. Eur. J. 2014, 20, 10695-10702. [CrossRef]

19. Zhang, X.; Vieru, V.; Feng, X.; Liu, J.-L.; Zhang, Z.; Na, B.; Shi, W.; Wang, B.-W.; Powell, A.K.; Chibotaru, L.F.; et al. Influence of Guest Exchange on the Magnetization Dynamics of Dilanthanide Single-Molecule-Magnet Nodes within a Metal-Organic Framework. Angew. Chem. Int. Ed. 2015, 54, 9861-9865. [CrossRef]

20. Huang, G.; Fernandez-Garcia, G.; Badiane, I.; Camarra, M.; Freslon, S.; Guillou, O.; Daiguebonne, C.; Totti, F.; Cador, O.; Guizouarn, T.; et al. Magnetic Slow Relaxation in a Metal-Organic Framework Made of Chains of Ferromagnetically Coupled Single-Molecule Magnets. Chem. Eur. J. 2018, 24, 6983-6991. [CrossRef]

21. Dogaheh, S.G.; Heras Ojea, M.J.; Piquer, L.R.; Artús Suàrez, L.; Khanmohammadi, H.; Aromí, G.; Sañudo, E.C. Co II and Cu II Fluorescent Complexes with Acridine-Based Ligands. Eur. J. Inorg. Chem. 2016, 2016, 3314-3321. [CrossRef]

22. Gholizadeh Dogaheh, S.; Khanmohammadi, H.; Sañudo, E.C. Double-decker luminescent ytterbium and erbium SMMs with symmetric and asymmetric Schiff base ligands. New J. Chem. 2017, 41, 10101-10111. [CrossRef]

23. Menelaou, M.; Ouharrou, F.; Rodríguez, L.; Roubeau, O.; Teat, S.J.; Aliaga-Alcalde, N. Dy(III)- and Yb(III)-curcuminoid compounds: Original fluorescent single-ion magnet and magnetic near-IR luminescent species. Chemistry 2012, 18, 11545-11549. [CrossRef]

24. Soussi, K.; Jung, J.; Pointillart, F.; Le Guennic, B.; Lefeuvre, B.; Golhen, S.; Cador, O.; Guyot, Y.; Maury, O.; Ouahab, L. Magnetic and photo-physical investigations into Dy-III and $\mathrm{Yb}$-III complexes involving tetrathiafulvalene ligand. Inorg. Chem. Front. 2015, 2, 1105-1117. [CrossRef]

25. Pointillart, F.; Le Guennic, B.; Cauchy, T.; Golhen, S.; Cador, O.; Maury, O.; Ouahab, L. A series of tetrathiafulvalene-based lanthanide complexes displaying either single molecule magnet or luminescence-Direct magnetic and photo-physical correlations in the ytterbium analogue. Inorg. Chem. 2013, 52, 5978-5990. [CrossRef]

26. Marin, R.; Brunet, G.; Murugesu, M. Shining new light on multifunctional lanthanide single-molecule magnets. Angew. Chemie Int. Ed. 2019.

27. Jia, J.H.; Li, Q.W.; Chen, Y.C.; Liu, J.L.; Tong, M.L. Luminescent single-molecule magnets based on lanthanides: Design strategies, recent advances and magneto-luminescent studies. Coord. Chem. Rev. 2019, 378, 365-381. [CrossRef]

28. Benmansour, S.; Hernández-Paredes, A.; Mondal, A.; López Martínez, G.; Canet-Ferrer, J.; Konar, S.; Gómez-García, C.J. Slow relaxation of the magnetization, reversible solvent exchange and luminescence in 2D anilato-based frameworks. Chem. Commun. 2020, 56, 9862-9865. [CrossRef] [PubMed]

29. Salinas Uber, J.; Estrader, M.; Mathonière, C.; Clérac, R.; Roubeau, O.; Aromí, G. Photochromic Performance of Two Cu(II)-OneDimensional Solvatomorphs Controlled by Intermolecular Interactions. Cryst. Growth Des. 2016, 16, 4026-4033. [CrossRef]

30. Estrader, M.; Salinas Uber, J.; Barrios, L.A.; Garcia, J.; Lloyd-Williams, P.; Roubeau, O.; Teat, S.J.; Aromí, G. A Magneto-optical Molecular Device: Interplay of Spin Crossover, Luminescence, Photomagnetism, and Photochromism. Angew. Chem. Int. Ed. 2017, 56, 15622-15627. [CrossRef] [PubMed]

31. Bartolome, E.; Bartolome, J.; Sedona, F.; Lobo-Checa, J.; Forrer, D.; Herrero-Albillos, J.; Piantek, M.; Herrero-Martin, J.; Betto, D.; Velez-Fort, E.; et al. Enhanced Magnetism through Oxygenation of FePc/Ag(110) Monolayer Phases. J. Phys. Chem. C 2020, 124, 13993-14006. [CrossRef]

32. Li, Q.-P.; Yan, B. Luminescent GaN semiconductor based on surface modification with lanthanide complexes through an ionic liquid bridge. RSC Adv. 2012, 2, 10840-10843. [CrossRef]

33. Bahuleyan, B.K.; Toussaint, K.; Rinnert, H.; Vallon, R.; Molinari, M.; Chuburu, F.; Cadiou, C. Silicon Wafer Functionalization with a Luminescent $\mathrm{Tb}(\mathrm{III})$ Coordination Complex: Synthesis, Characterization, and Application to the Optical Detection of NO in the Gas Phase. Molecules 2019, 24, 1914. [CrossRef]

34. Heinke, L.; Tu, M.; Wannapaiboon, S.; Fischer, R.; Woll, C. Surface-mounted metal-organic frameworks for applications in sensing and separation. Microporous Mesoporous Mater. 2015, 216, 200-215. [CrossRef] 
35. Doustkhah, E.; Hassandoost, R.; Khataee, A.; Luque, R.; Assadi, M.H.N. Hard-templated metal-organic frameworks for advanced applications. Chem. Soc. Rev. 2021, 50, 2927-2953. [CrossRef] [PubMed]

36. Ashworth, D.J.; Foster, J.A. Metal-organic framework nanosheets (MONs): A new dimension in materials chemistry. J. Mater. Chem. A 2018, 6, 16292-16307. [CrossRef]

37. Pepi, B.; Contreras-Pereda, N.; Suárez-García, S.; Hayatia, P.; Benmansourb, S.; Pascal, R.; Morsalid, A.; Ruiz-Molina, D. Solventtuned ultrasonic synthesis of 2D coordination polymer nanostructures and flakes. Ultrason. Sonochem. 2021, 72, 105425. [CrossRef] [PubMed]

38. León-Alcaide, L.; López-Cabrelles, J.; Espallargas, G.M.; Coronado, E. 2D magnetic MOFs with micron-lateral size by liquid exfoliation. Chem. Commun. 2020, 56, 7657-7660. [CrossRef]

39. González, J.; Sevilla, P.; Gabarró-Riera, G.; Jover, J.; Echeverría, J.; Fuertes, S.; Arauzo, A.; Bartolomé, E.; Sañudo, E.C. A multifunctional Dysprosium-carboxylato 2D metallorganic framework. Angew. Chem. Int. Ed. 2021, 60, 12001-12006. [CrossRef] [PubMed]

40. Liu, C.-M.; Xiong, M.; Zhang, D.-Q.; Du, M.; Zhu, D.-B. Two- and three-dimensional lanthanide-organic frameworks constructed using 1-hydro-6-oxopyridine-3-carboxylate and oxalate ligands. Dalton Trans. 2009, 5666-5672. [CrossRef] [PubMed]

41. López-Cabrelles, J.; Mañas-Valero, S.; Vitórica-Yrezábal, I.J.; Bereciartua, P.J.; Waerenborgh, J.A.; Rodríguez-Velamazán, J.C.; Vieira, B.J.C.; Davidovikj, D.; Steeneken, P.G.; Zant, H.S.J.; et al. Isoreticular two-dimensional magnetic coordination polymers prepared through pre-synthetic ligand functionalization. Nat. Chem. 2018, 10, 1001-1007. [CrossRef] [PubMed]

42. Temple, P.A.; Hathaway, C.E. Multiphonon Raman Spectra of Silicon. Phys. Rev. B 1973, 7, 3685. [CrossRef]

43. González, J.C.; Mestres, N.; Puig, T.; Gázquez, J.; Sandiumenge, F.; Obradors, X.; Usoskin, A.; Jooss, C.; Freyhardt, H.C.; Feenstra, R. Biaxial texture analysis of YBa2Cu3O7-coated conductors by micro-Raman spectroscopy. Phys. Rev. B 2004, 70, 094525. [CrossRef] 